Baselga, J. 6

Bell, R. 39

Di Leo, A. 25

Dowsett, M. 25

Gianni, L. 47

Hammond, L.A. 6

Horten, B. 25
Penault-Llorca, F. 25

Piccart, M. 57

Ranson, M. 17

Sliwkowski, M.X. 17

Tan-Chiu, E. 57

Ullrich, A. 1

Vijver, M. van de 33

\title{
Subject Index Vol. 63, Suppl. 1, 2002
}

\section{ABX-EGF 17}

Adjuvant therapy 57

Anthracyclines 47

Breast cancer 25, 33, 47

2C4 17

Cancer 1

Cetuximab 17

Chromogenic in-situ hybridization assay 33 CI-1033 6

COX2 inhibitors 47

EGFR 1, 6

Enzyme-linked immunosorption assay 33

Fluorescence in-situ hybridization 33

Gene therapy 1

Head and neck cancer 6

HER 1, 6

HER 1 tyrosine-kinase inhibitors 47

HER2 25, 33, 39, 57

Herceptin ${ }^{\circledR} 17,25,39,47,57$
Hormonal therapy 47

h-R3 17

Immunohistochemistry 33

Iressa TM 6

Maytansine 17

Metastatic breast cancer 39

Monoclonal antibodies 1, 17

Non-small cell lung cancer 6

Ovarian cancer 6

Pathology 25

PKI-166 6

Polymerase chain reaction 33

Primary breast cancer 57

Receptor tyrosine kinases 1

Tarcevah $^{\mathrm{TM}} 6$

Targeted therapies 1, 47

Trastuzumab 17

Tumor markers 25

Tyrosine-kinase inhibitor 1, 6

\section{KARGER}

(c) 2002 S. Karger AG, Basel

Fax +41613061234 